\title{
Improvement of Home Portable Rehabilitation Device for Upper-Limbs*
}

\author{
So SHIMOOKA**, Tetsuya AKAGI **, Shujiro DOHTA **, Wataru KOBAYASHI** \\ and Takashi SHINOHARA **
}

\begin{abstract}
Based on Japanese aging society, a welfare pneumatic equipment to execute a rehabilitation for the temporally injured elderly and disabled is actively researched and developed. In the previous study, a portable rehabilitation device using extension type flexible pneumatic actuators (EFPAs), built-in quasi-servo valves and built-in displacement sensors using a wire type linear potentiometer was proposed and tested. In this study, to increase the generated force and bending stiffness of the device, the actuator that has three parallel arranged EFPAs with sponge cover was proposed and tested. As a result, the generated force of the improved actuator becomes 1.5 times than the previous one. The portable rehabilitation device using the improved actuator was proposed and tested. The built-in attitude control system using valves, sensor and an embedded controller was developed. The attitude control based on the analytical model of the device was also proposed. As a result, it can be found that the displacement of each actuator can trace well for each desired position.
\end{abstract}

Keywords: Portable rehabilitation device, Extension-type-flexible-pneumatic actuator (EFPA), Integrated type EFPA, Analytical model for attitude control, Integrated attitude control system using valves and micro-computer

\section{Introduction}

Since the beginning of the 21 st century, wearable pneumatic equipments to support nursing care and power assist for welfare work for the elderly and the disabled using pneumatic soft actuators ${ }^{1)}$ have been actively researched and developed. K. Yamamoto developed a wearable power assist suit for nursing care using bellows type actuators ${ }^{2}$. $\mathrm{T}$. Noritsugu and H. Kobayshi also developed power assisted wear using pneumatic rubber artificial muscles ${ }^{3-5)}$. These methods are to aim to increase force for welfare workers and the elderly. On the other hands, as taking account of "Quality of Life" for the patient or elderly, a rehabilitation device that can help to recover their physical ability after injured is also required. In Japanese law, patients can receive rehabilitation for only 30 minutes a day from Physical Therapist ("PT" for short) and Occupational Therapist (“OT” for short). However, most of PT and OT think that the rehabilitation of 30 minutes is insufficient. They think that it is better to do a voluntary rehabilitation by patients themselves adding to the PT/OT's treatment time. Based on these conditions, as a research on rehabilitation device giving passive exercise, H. Taniguchi and $\mathrm{H}$. Kawasaki developed a rehabilitation device for finger joints ${ }^{6)-7)}$. M. Takaiwa also developed a rehabilitation device for wrist ${ }^{8)}$. In ideal, it is better that patients can release these

\footnotetext{
"Manuscript received January 15, 2019

** Okayama University of Science

(1-1 Ridai-cho, Kita-ku, Okayama, 700-0005 Japan)

E-mail: t17sd01ss@ous.jp
}

devices immediately if they feel dangerous in the rehabilitation. The purpose of our study is to develop a home rehabilitation device that can give passive exercise for patient with hemiplegia or physical disability so that the device can be safely used at home without special knowledge. A wearable type rehabilitation device is not easily acceptable for patient who would like to use it by himself. Therefore, a portable or stationary type rehabilitation device is suitable as a desired device. In addition, a rehabilitation device is not used in a long period for one user. Figure 1 shows the target image of our proposed rehabilitation system. In a typical pneumatic drive system using wearable actuator, valves and controller (personal computer) are most occupied in whole cost and mass of the system. The valve is most expensive equipment in pneumatic driving system. Therefore, in our previous study, various small-sized quasi-servo valves using low-cost on/off valves and control system using tiny embedded controllers have been developed ${ }^{9)-12)}$. In addition, after therapy, it needs much cost to wash the device in order to reuse it. Therefore, as taking account of cost burden for user, it is better to produce the device at low cost so that it can be disposable. In particular, the low-cost actuator unit is desirable. Based on these requirements mentioned above, in this study, a portable rehabilitation device with relative larger moving area that can give passive exercise for whole upper limb while holding it by both hands is decided as a target device. In the previous study, the portable rehabilitation device using flexible spherical actuator that can provide 
passive exercise for the upper limb by changing the position of holding hands was proposed and tested ${ }^{13)}$. To realize both compact configuration and larger moving area of the desired rehabilitation device, a low-cost extension-type-flexiblepneumatic actuator ("EFPA" for short) with a longer stroke was proposed and tested ${ }^{4), 14)-15)}$. The EFPA can be easily constructed by using the water supply tube on the market ${ }^{14)}$. However, the bending stiffness of the tested EFPA is not enough to apply a force to arms and shoulders.

In this paper, the development of EFPA with suitable bending stiffness and improvement of its generated force are described. In order to improve the generated force, the integrated type EFPA using three improved EFPA will also be described.

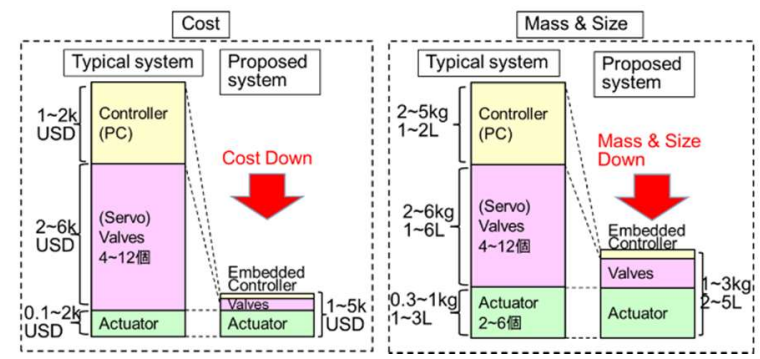

Fig. 1 Target image of proposed rehabilitation system

\section{Nomenclatures}

$\begin{array}{lll}e_{i} & : & \text { error between desired and controlled } \\ & & \text { displacement [m] } \\ D_{i} & : & \text { input duty ratio [\%] } \\ k_{p i} & : & \text { proportional gain }[\% / \mathrm{m}] \\ l_{i} & : & \text { length from the standard of EFPA }[\mathrm{m}] \\ L & : & \text { central length of the integrated EFPA [m] } \\ L_{r i} & : & \text { reference length of each actuator }[\mathrm{m}] \\ L_{y i} & : & \text { output length of each actuator }[\mathrm{m}] \\ R & : & \text { radius of curvature of the device }[\mathrm{m}] \\ r & : & \text { distance between the center of the arm } \\ & & \text { and the center of each actuator }[\mathrm{m}] \\ u_{i} & : & \text { manipulated variable [\%] } \\ \alpha & : & \text { bending direction angle }[\mathrm{rad}] \\ \beta & : & \text { bending angle [rad] } \\ \text { Subscript } & & \\ i & : & \text { number of each actuator }\end{array}$

\section{Design Concept of Rehabilitation Device}

In order to develop the rehabilitation device for the upper limbs, it is needed to estimate the force required to lift the arms and shoulders. The weight of arm is about $6 \%$ of the whole body weight ${ }^{16)}$. We assumed that the required torque of the target device is the torque to lift a half of the mass of the arm from the experience that the portable rehabilitation device using flexible pneumatic cylinder ${ }^{13)}$ could lead a passive exercise for both upper limbs by using of torque of about 2 Nm. According to PT's opinion, they estimate that the preliminary developed device $\left.{ }^{14}\right)$ is useful to apply to the rehabilitation device that patient can use it by him or herself at home, because the displacement of the device can change naturally according to stiffness of patient's upper limbs. It means that the maximum force of the device needs to set around the required force for lifting up arms. As taking account that the average body weight of Japanese elderly is about $61 \mathrm{~kg}^{17)}$, the desired moving area of the device with radius of $0.25 \mathrm{~m}$ and setting position of actuator with distance of $0.07 \mathrm{~m}$ from the center of the device, the generated torque of about $5.0 \mathrm{Nm}$ is required to lift and move both arms and shoulders. Therefore, the generated pulling force of EFPA (about $40 \mathrm{~N})^{14)}$ is insufficient to lift and move arms and shoulders by changing the position of both hands. In order to lift and move arms and shoulders, it seems that the minimum generated force of more than about $71 \mathrm{~N}$ is required. In this study, we decided that desired maximum force of the actuator is set between 1.5 times and twice force for lifting both arms, that is between $106 \mathrm{~N}$ and $140 \mathrm{~N}$. Therefore, it is necessary to improve generated force of the actuator in order to satisfy these specifications.

\section{Extension-Type-Flexible-Pneumatic Actuator}

Figure 2 shows an external view and schematic diagram of the EFPA developed in the previous study ${ }^{14)}$. The actuator consists of a rubber tube covered with a ruffled fabric sleeve. The ruffled fabric tube is used as an ordinal water supply tube (Taisho Industry Co. Ltd., Magic hose). The rubber tube in the sleeve has an inner diameter of $6 \mathrm{~mm}$, outer diameter of 9.5 $\mathrm{mm}$, and length of $200 \mathrm{~mm}$. The material cost of the actuator is low, that is about 5 US dollars per $1 \mathrm{~m}$. The displacement of the actuator saturates for the supply pressure of more than $400 \mathrm{kPa}$. The actuator can extend until about $235 \%$ of its original length when the input pressure of $400 \mathrm{kPa}$ is applied. However, the generated force of the EFPA is not so large. The maximum pulling force is about $40 \mathrm{~N}$. The maximum generated force of the actuator depends on the elastic property of the rubber tube, and it is proportional to thickness of the rubber tube. The displacement of actuator is inversely proportional to the thickness of the rubber tube. In addition, the bending stiffness of actuator is not enough to provide a passive exercise for arms and shoulder. 


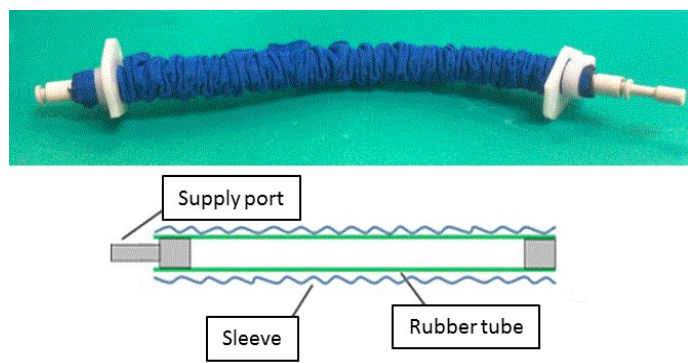

Fig. 2 Overview and schematic diagram of EFPA in previous study

Therefore, it is necessary to improve the bending stiffness and generated force of the EFPA compared with the previous actuator. As a method to increase the generated force, the thick silicone rubber tube with an inner diameter of $8 \mathrm{~mm}$ and an outer diameter of $11 \mathrm{~mm}$ was used. The silicone rubber tube was also selected because of good flexibility, heat resistance and water resistance.

Figure 3 shows the overview and schematic diagram of the improved EFPA. In the improved EFPA, a bellows type of ruffled fabric tube (Swiftrans Co. Ltd., Stretching hose) was changed. The construction of improved EFPA is same as the previous one. The sleeve has inner diameter of $12 \mathrm{~mm}$, outer diameter of $20 \mathrm{~mm}$. By using the sleeve with a bellows, the actuator can extend uniformly and bending stiffness of the actuator is also improved.
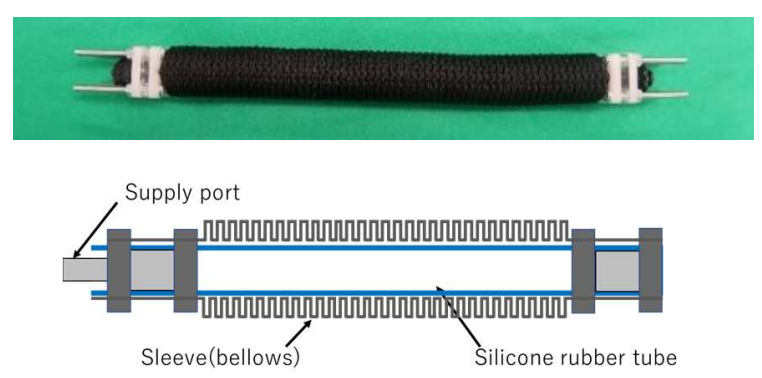

Fig. 3 Overview and schematic diagram of the improved EFPA

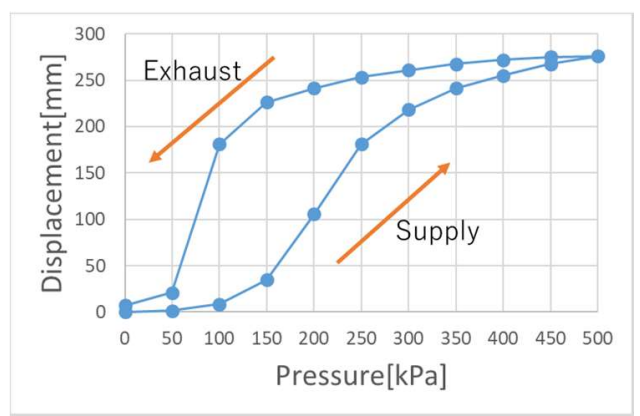

Fig. 4 Relation between supply pressure and displacement of the improved EFPA
Figure 4 shows the relation between the supply pressure and displacement of EFPA. From Fig.4, it can be found that the maximum displacement of the improved EFPA is $276 \mathrm{~mm}$, that is, a $253 \%$ extension of the original length. It is also found that there is nonignorable hysteresis in the relation between supply pressure and displacement of the actuator. It is caused by the friction between the rubber tube and the sleeve.

Figure 5 shows the relation between the supply pressure and the generated pulling force of the improved EFPA. In Fig.5, each symbol shows the number of measurements. In the experiment, under the condition when the supply pressure of $500 \mathrm{kPa}$ is applied as a saturated pressure, the generated pulling force is measured by decreasing supply pressure. The maximum generated force of the improved EFPA is about 60 $\mathrm{N}$. The generated force of the EFPA is improved compared with the previous one (that is about $40 \mathrm{~N}$ ). However, the bending stiffness of single EFPA is low. Therefore, it is necessary to improve the stiffness of the EFPA.

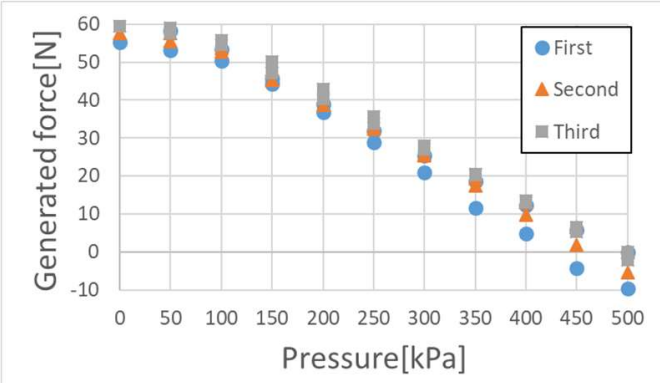

Fig. 5 Relation between supply pressure and generated pulling force of the improved EFPA

\section{Integrated Type EFPA}

In order to get the desired torque $(>5.0 \mathrm{Nm})$ of the portable rehabilitation device for both arms, the bending stiffness of the EFPA must be improved. However, the EFPA in the device is also required flexibility so that the device can not hurt a patient. In addition, the pressurized EFPA has suitable bending stiffness by expanding the rubber tube in the sleeve. Therefore, the EFPA must have bending stiffness when the actuator is not pressurized. In order to realize these conflicting demands, an integrated type EFPA using improved EFPAs as shown in Fig. 6 is proposed and tested. The integrated type EFPA consists of three EFPAs with an original length of 200 $\mathrm{mm}$ and covered sponges. The length of the EFPA is decided so that the maximum length of actuator becomes the typical shoulder width of about $450 \mathrm{~mm}$. In order to realize the same bending stiffness for every direction, EFPAs are arranged every $120 \mathrm{deg}$. at radius of $25 \mathrm{~mm}$ from the center of the actuator. To realize the bending stiffness in lower input 
pressure and to keep a parallel arrangement of the three EFPAs, the compressed and laminated ring-shaped sponges with a thickness of $50 \mathrm{~mm}$ were used. The sponge was cut by using a laser cutting machine. The cutting accuracy is within about $0.2 \mathrm{~mm}$. There is also no clearance between EFPA and hole of the sponge to prevent shear slip. From the result of preliminary experiment, the sponge with density $18-22 \mathrm{~kg} / \mathrm{m}^{3}$ was used from view point of lower friction and suitable bending stiffness that is depended on outer diameter of the sponge.

The operating principle to get suitable bending stiffness is as follows. As a sponge has a property of spring elements, the compressed sponge works as a compression spring. By adjusting outer diameter of sponges covered by three EFPAs, the initial bending stiffness can be controlled. In the tested actuator, sponges with the outer diameter of $90 \mathrm{~mm}$ were selected so that the actuator could not occur buckling while actuation. In addition, the sponge was selected because of its flexibility, lightweight and inexpensiveness compared with the rigid spring. The setting position of each EFPA in the sponge was decided so that EFPA could not contact with each other. The number of inserted sponges in the actuator was also decided so that the natural thickness of laminated sponges became the initial length of EFPAs. It can be confirmed that the shape of integrated type EFPA can maintain even if it is arranged like a cantilever. The integrated EFPA has a length of $235 \mathrm{~mm}$, a width of $90 \mathrm{~mm}$ and a height of $90 \mathrm{~mm}$.
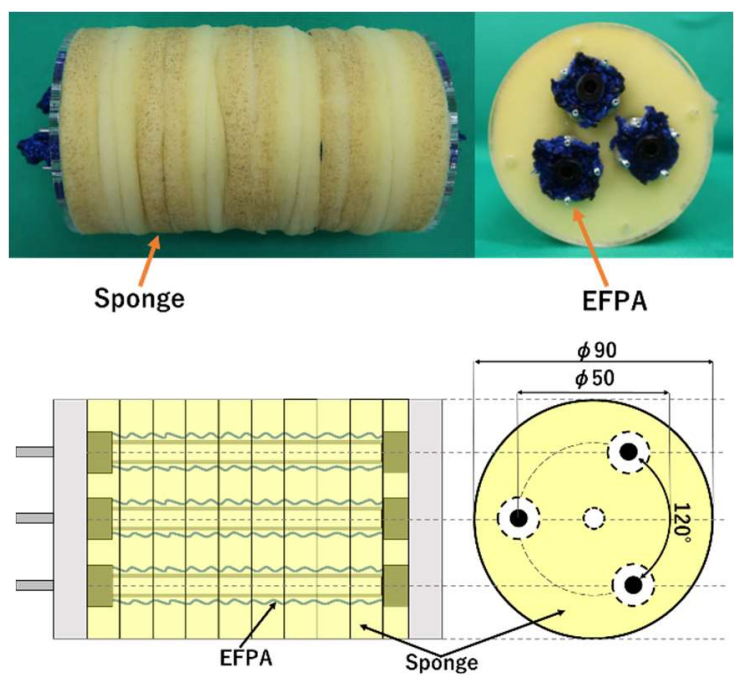

Fig. 6 Overview and schematic diagram of integrated type EFPA

$$
\text { with sponge }
$$

Figure 7 shows relation between the supply pressure and the generated pulling force of the integrated type EFPA without sponges. Figure 8 shows the result using the integrated type EFPA with sponge. In Figs.7 and 8, each symbol shows the number of measurements. In the experiment, under the condition when the supply pressure of $400 \mathrm{kPa}$ is applied, the generated pulling force is measured by decreasing supply pressure. From Figs.7 and 8, the maximum generated pulling force of the actuator with and without sponges are $90 \mathrm{~N}$ and $126 \mathrm{~N}$, respectively. It can be seen that the generated force of the actuator with sponges is larger than the case using the actuator without sponges even if the frictional force between sponges and EFPAs is increased. We think that it is because the bucking and irregular deformation of each EFPA does not occur.

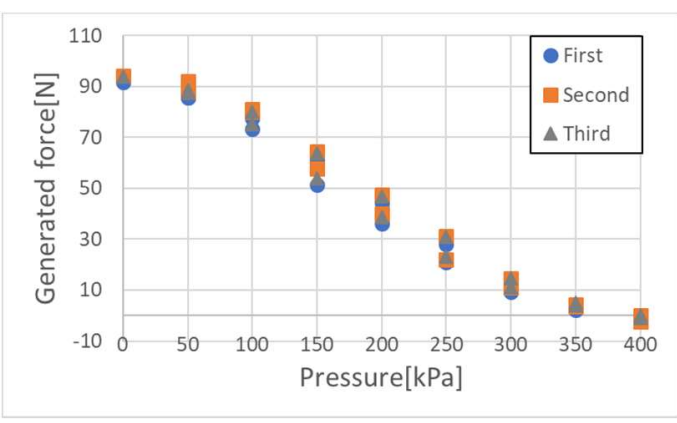

Fig. 7 Relation between supply pressure and generated pulling force of integrated type EFPA without sponge

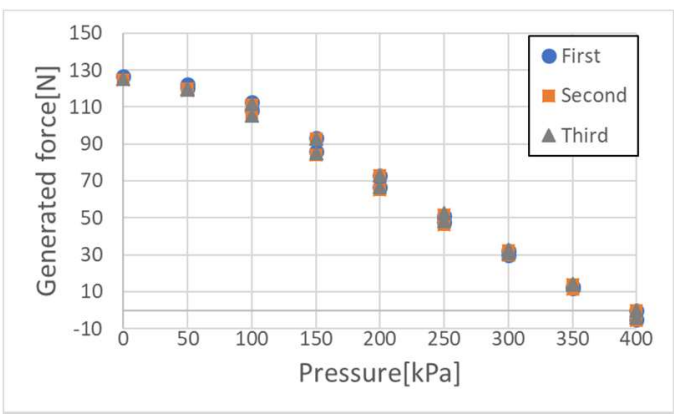

Fig. 8 Relation between supply pressure and generated pulling force of integrated type EFPA with sponge

Figure 9 shows the relation between the ratio of deflection to length of the actuator and generated force of the integrated type EFPA. In experiment, we measure the vertical pulling force acted at the top end of the actuator under the condition when the actuator is bent with various supply pressure as shown in Fig.9. The inclination of graph means the bending stiffness of the actuator. As a result, it is found that the bending stiffness of the improved actuator increases, even if the bending stiffness of the previous actuator could not be measured with no supply pressure. It is also found that the improved actuator has the bending stiffness of more than the certain value $(3.4 \mathrm{~N} /-)$ with various supply pressure. 


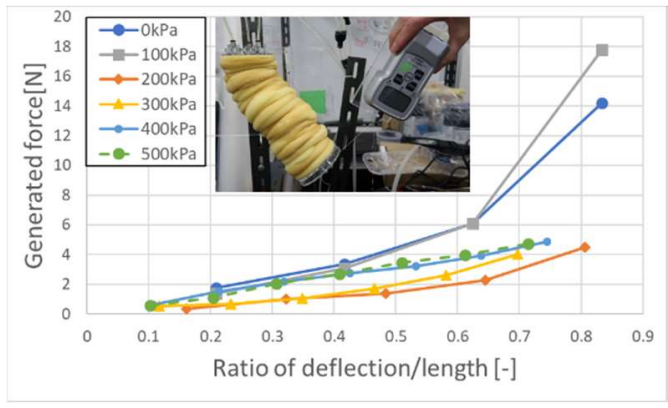

Fig. 9 Relation between ratio of deflection to length of the actuator and generated force

\section{Improved Portable Rehabilitation Device}

Figures 10 shows the improved portable rehabilitation device for upper limbs using integrated type EFPAs. The tested rehabilitation device consists of three tested integrated type EFPAs, three wire type linear potentiometer ${ }^{18)-19)}$ to measure the displacement of each EFPA, three quasi-servo valves $^{9)-12)}$ to drive EFPAs and a micro-computer (Renesas Co. Ltd., SH7125) to control the attitude of the device.

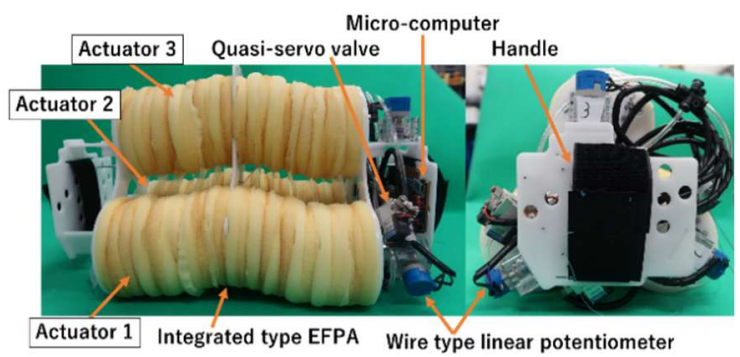

Fig. 10 Overview of improved portable rehabilitation device for upper-limbs

In order to get the desired torque mentioned above $(5.0 \mathrm{Nm})$, each integrated type EFPA is arranged every $120 \mathrm{deg}$. at radius of $70 \mathrm{~mm}$ from the center of both end plates. The calculated maximum torque of the device is about $9.0 \mathrm{Nm}$ for both arms and shoulders. In order to keep a parallel arrangement of three integrated type EFPAs, triangle-shaped plastic film with three holes are set between sponges. A plastic plate with thickness of $3 \mathrm{~mm}$ is inserted into the middle position of each EFPA.

The wire type potentiometer is located at the center of the integrated type EFPA to measure the displacement of the actuator. The pulling force of each linear potentiometer is changed between 0.3 and $1.2 \mathrm{~N}$. This value is about one hundredth of maximum force of the actuator. We recognize that influence of this pulling force does not affect the control performance so much.
Figure 11 shows the schematic diagram of the attitude control system. To control the displacement of each actuator, quasi-servo valves ${ }^{10)}$ that consists of two on/off-type control valves (KOGANEI Co. Ltd., G010HE-1) as shown in Fig.12 was used. Compared with previous device ${ }^{14)}$, the proposed device needs more flow rate, because the proposed device has more actuators than the previous one in order to increase the generated force. The maximum flow rate of the tested valve is about 35 litter/min. This is about 2.3 times more than the previous one of $1.5 \mathrm{litter} / \mathrm{min}$. The material cost of the on/off valve is about 35 US dollars. The size of the valve without a typical tube connector is $40 \times 20 \times 26 \mathrm{~mm}$. The mass of the valve is $38 \mathrm{~g}$. This is only 1.58 times larger than the previous one of $24 \mathrm{~g}$.

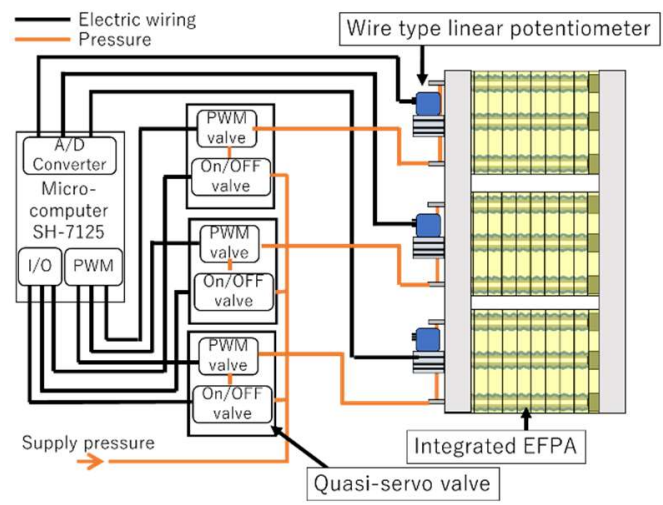

Fig. 11 Schematic diagram of portable rehabilitation device for upper-limbs

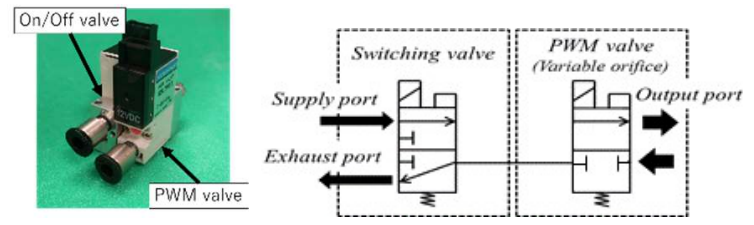

Fig. 12 Overview and construction of quasi-servo valve

The position control of each integrated EFPA in the device is done as follows. First, the wire-type linear potentiometer measures each displacement of the center of integrated type EFPA through A/D converter in the micro-computer. The deviation from the desired displacement is calculated by the micro-computer. The control input for each quasi-servo valve is also calculated based on P control scheme. P control scheme and input value of each valve in quasi-servo valve are expressed by following equations.

$$
u_{i}=k_{p i} \cdot e_{i}
$$


Switching valve:

$$
\begin{gathered}
u_{i}>0 \text { Switching valve: on (Supply) } \\
u_{i}<0 \text { Switching valve: off (Exhaust) } \\
u_{i}=0 \text { Switching valve :hold }
\end{gathered}
$$

PWM valve:

$$
D_{i}=u_{i}+47.5
$$

where $u_{i}, K_{p i}$, and $e_{i}$ mean the input duty ratio for supply and exhaust, the proportional gain and the error between the desired and controlled displacement, respectively. Input duty ratio $D_{i}$ for each PWM valve is added $47.5 \%$ to compensate dead zone of output flow rate of the valve. The value of $47.5 \%$ was decided from the previous result that is a relation between input duty ration and output flow rate of the quasi-servo valve with PWM period of $5 \mathrm{~ms}^{9}$. This value means the adjusted value from the threshold duty ratio (40-45\%) of dead zone of the output flow rate. Figure 13 shows the transient responses of displacement of each EFPA for bending motion of the tested rehabilitation device. In the experiment, each displacement was measured while both hands held both holders of the device. The middle plastic plate was also set on the table by wires as shown in Fig.14. In Fig.13, the broken and solid lines show the desired and controlled displacement of the actuator, respectively. As a result, it can be seen that the controlled displacement agrees with each desired displacement. However, in the result of displacement of actuator 3, it can be found that the error is larger than other cases. It seems that it is caused by disturbance from gravity and so on.

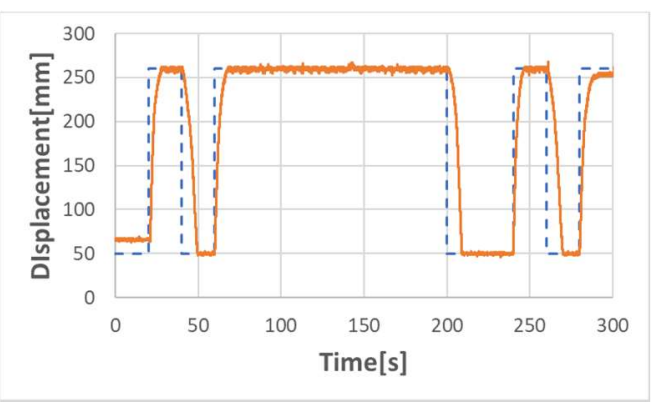

(a) Actuator 1

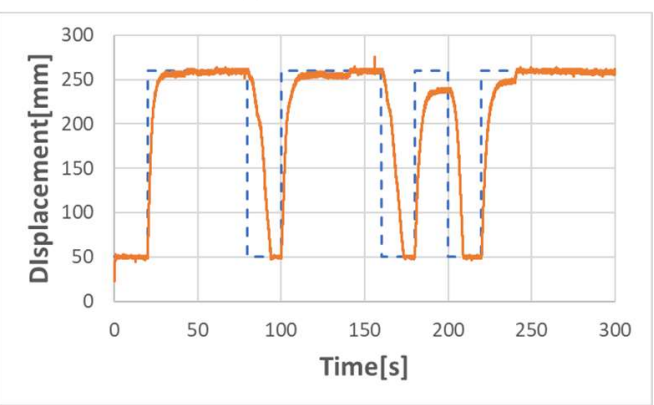

(b) Actuator 2

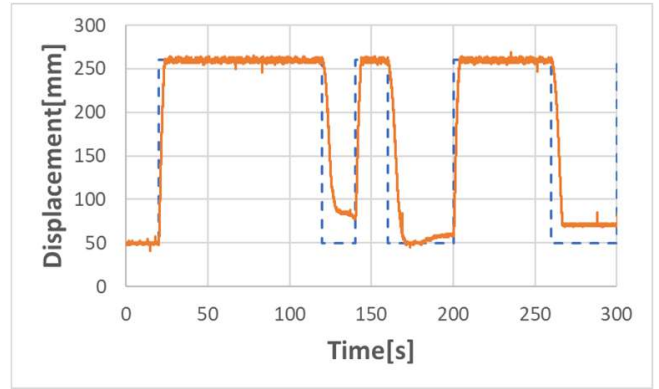

(c) Actuator 3

Fig. 13 Transient response of displacement of each actuator in tested rehabilitation device for bending motion

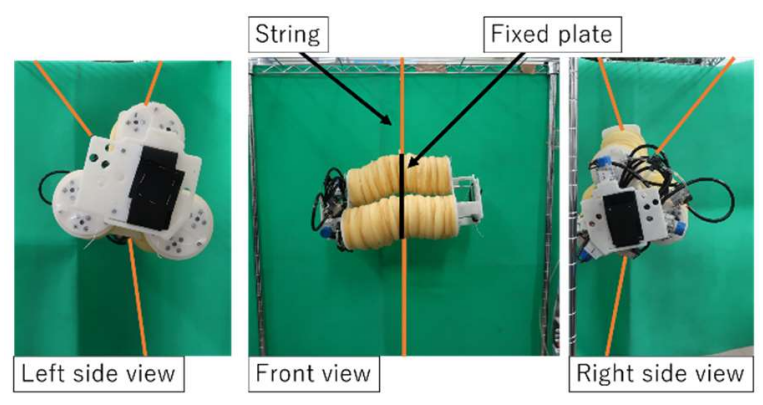

Fig. 14 Overview of experimental condition using the device

\section{Attitude Control Based on Analytical Model}

To control the attitude of the tested device so as to trace the target trajectory, an analytical model that can calculate the desired length of each EFPA from the attitude of the device is required $^{20)}$. Figure 15 (a) shows the analytical model of the rehabilitation device. Figure 15 (b) shows the projection drawing of each actuator from the fixed middle plate as definition of length of each actuator. As shown in Figs.15 (a) and (b), the center of the fixed middle plate of the device is defined as an origin. The integrated type EFPA located on the $\mathrm{Z}$ axis is defined as actuator 3, and the other actuators arranged in a counterclockwise direction from the position of actuator 3 are defined as actuator 1 and 2, respectively. $l_{1}, l_{2}$, and $l_{3}$ as shown in bold lines of Fig. 15 are half lengths of each arc shaped actuator from the fixed plate, respectively. As assuming each actuator becomes circular arc while bending the device, from the geometric relationship as shown in Figs. 14 (a) and (b), the following equations can be obtained:

$$
\begin{gathered}
R=\frac{l}{\beta}, \\
l_{1}=(R-r \cdot \cos \alpha) \cdot \beta, \\
l_{2}=\left\{R-r \cos \left(\frac{2 \pi}{3}-\alpha\right)\right\} \cdot \beta,
\end{gathered}
$$




$$
\begin{gathered}
l_{3}=\left\{R-r \cos \left(\frac{4 \pi}{3}-\alpha\right)\right\} \cdot \beta, \\
L_{r i}=2 l_{i},
\end{gathered}
$$

where $R, r, \alpha$ and $\beta$ are the radius of curvature, the distance $(70 \mathrm{~mm})$ between the center of each EFPA and the origin, the bending directional angle and the bending angle of the device, respectively. The attitude of the device can be decided by the bending directional angle $\alpha$, the bending angle $\beta$ and the central displacement $l$. By using Eqs. (4) to (8), therefore, the desired length of each actuator $L_{r l}, L_{r 2}$ and $L_{r 3}$ can be calculated.

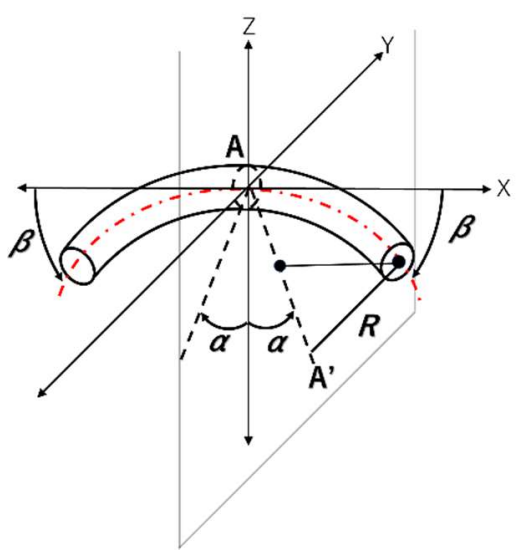

(a) Definition of angles $\alpha$ and $\beta$

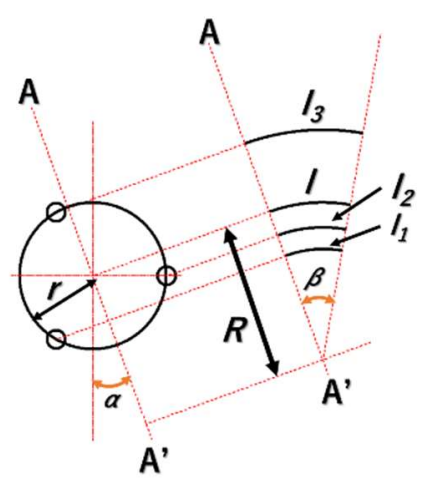

(b) Definition of lengths of each actuator

Fig. 15 Analytical model of the tested device

Figures 16 and 17 show the transient view of movement of the device and transient response of displacement of each EFPA in the device, respectively. In the experiment, the desired bending angle $\beta$ of $\pi / 4 \mathrm{rad}$ and the desired central half length $l$ of $190 \mathrm{~mm}$ were used. The bending directional angle $\alpha$ was periodically changed every 25 seconds from 0 to $2 \pi$. In Fig. 16, the solid and broken lines indicate the controlled and desired displacement of each actuator calculated by the model, respectively. As a result, it can be found that the controlled displacement of each actuator can almost trace each reference displacement. It seems that the error of each actuator displacement is caused by lack of exhaust flow rate of the quasi-servo valve from the result that the tracking delay is occurred when the actuator is contracting. It also seems that the device with longer actuator is more affected by the gravity like a cantilever.

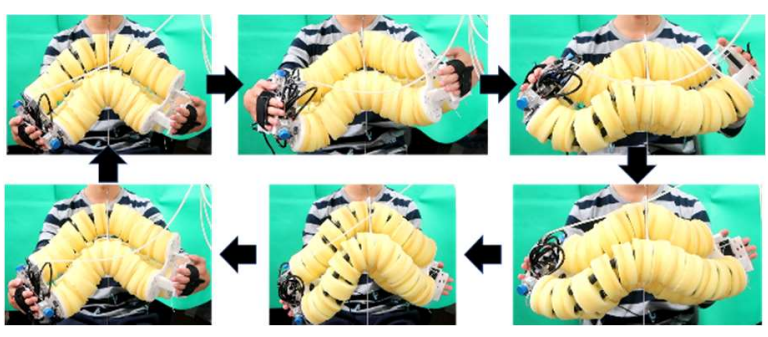

Fig. 16 Transient view of movement of the tested device

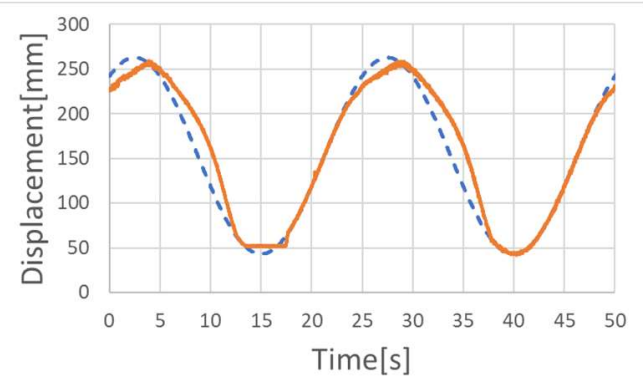

(a) Actuator 1

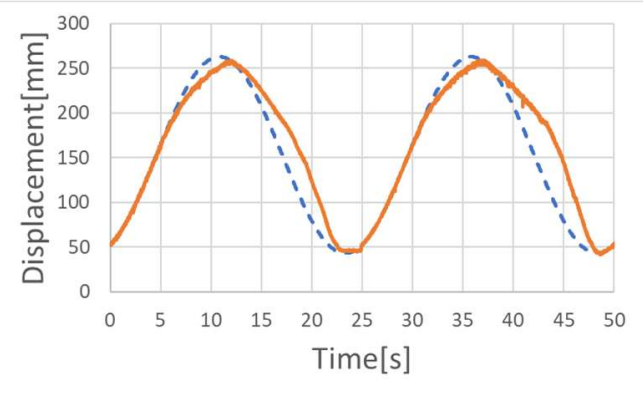

(b) Actuator 2

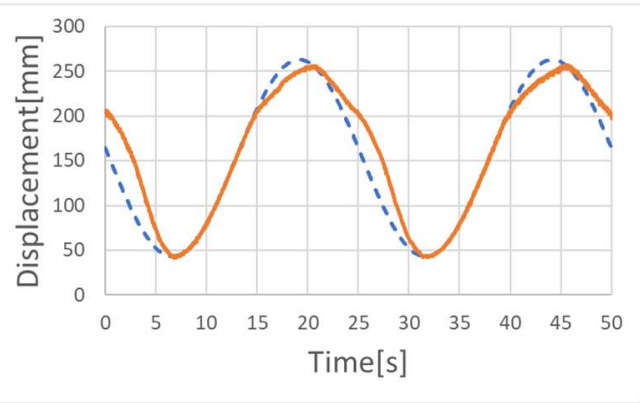

(c) Actuator 3

Fig. 17 Transient response of displacement of each actuator for tracking the desired trajectory 
As a future work, it is necessary to apply a compact valve with larger flow rate and suitable control scheme with gravity compensation to the system in order to get better attitude control performance.

\section{Conclusions}

As a home rehabilitation device that can give passive exercise for patient so that the device can be safely used at home without special knowledge, this study aiming to develop a rehabilitation device for upper-limbs using EFPA is summarized as follows.

The improved EFPA using bellows type sleeve was proposed and tested. As a result, the maximum generated pulling force of the improved EFPA was increased about 60 $\mathrm{N}$ compared with the previous one.

Based on the specification of target device, in order to increase the generated force and bending stiffness, the integrated type EFPA was proposed and tested. As a result, the maximum generated pulling force of $126 \mathrm{~N}$ could be obtained. The suitable bending stiffness was adjusted by changing the outer diameter of sponges. It was confirmed that the shape of integrated type EFPA could maintain even if it is arranged like a cantilever.

The portable rehabilitation using three integrated type EFPAs, wire type linear potentiometers, quasi-servo valves and a micro-computer for upper-limbs was proposed and tested. The analytical model that can calculate lengths of each EFPA from desired attitude of the device was also proposed. The trajectory tracking control using the model was carried out. As a result, it was confirmed that the controlled displacement for each actuator could trace the desire trajectory even if the low-cost sensor and embedded controller were used.

As future work, we are going to develop the rehabilitation device with a larger moving area and suitable bending stiffness of EFPA according to PT's opinion. In addition, we are going to aim to develop the multi functionable device that can be used by patients with various stage and investigate the effect of the rehabilitation using the device while we corporate with PT.

\section{Acknowledgment}

This study was supported by Japanese Ministry of Education, Culture, Sports, Science and Technology through a Financial Assistance Program for QOL Innovative Research (20122016) and a Grant-Aid for Scientific Research (C) (Subject No. 16K06202)

\section{References}

1) Nagata, Y. ed.: Soft Actuators, Forefront of Development, NTS Ltd., p.291-335 (2004)

2) Ishii, M., Yamamoto, K. and Hyodo, K.: Stand-Alone Wearable Power Assist Suit, Development and Availability, Journal of Robotics and Mechatronics, vol.17, p.575-583 (2005)

3) Noritsugu, T., Takaiwa, M. and Sasaki, D.: Development of Power Assist Wear Using Pneumatic Rubber Artificial Muscles, Journal of Robotics and Mechatronics, vol.21, p.607-613 (2009)

4) Noritsugu, T.: Pneumatic Soft Actuator for Human Assist Technology, Proceedings of the 6th JFPS International Symposium on Fluid Power, p.11-20 (2005)

5) Kobayashi, H., Shiban, T. and Ishida, Y.: Realization of all 7 motions for the upper limb by a muscle suit, Journal of Robotics and Mechatronics, vol.16, p.504-512 (2004)

6) Taniguchi, H., Wakimoto, S., Suzumori K.: Development of a hand rehabilitation system to prevent contracture for finger joints based on the therapy of occupational therapists (Massage a hand and range of motion exercises using pneumatic soft actuators), Journal of the Japan Society of Mechanical Engineers, Vol.80 p.TRANS0348 (2014)

7) Kawasaki, H., Ito, S., Ishigura, Y., Nishimoto, Y., Aoki, T., Abe, T., Sakaeda, H., Ojika, T., Mouri, T., Ueki, S. Hand Rehabilitation Assist Robot Designed with Assistance for Thumb Opposability, Journal of the Japan Society of Mechanical Engineers, Vol.74 p.3019-3027 (2008)

8) Takaiwa, M., Noritsugu, T., Sasaki, D.: Wrist Rehabilitation Using Pneumatic Parallel Manipulator $\sim$ Proposal of Rehabilitation Based on EMG signal , Transactions of the Japan Fluid Power System Society, Vol.43, p.85-91 (2012)

9) Zhao, F., Dohta, S. and Akagi, T.: Development and Analysis of Small-Sized Quasi-Servo Valve for Flexible Bending Actuator, Transactions of the Japan Society of Mechanical Engineers Series C, Vol.76, Issue 772, p.3665-3671 (2010) (in Japanese)

10) Shimooka, S., Dohta, S., Akagi, T., Moriwake, Y. and Zhao, F.: Estimation of Pressure Control Performance in Low-Cost Quasi-Servo Valve Using Embedded Controller, Lecture Notes in Electrical Engineering 293, Volume 1, Springer, p.359-366 (2014) 
11) Shimooka, S., Dohta, S., Akagi, T. and Moriwake, Y.: Analysis and Simulation of Small-Sized Quasi-Servo Valve Using Tiny On/Off Control Valve, Lecture Notes in Electrical Engineering 345, Springer, p.59-66 (2015)

12) Shimooka, S., Dohta, S., Akagi, T. and Moriwake, Y.: Position Control of Rubber Artificial Muscle Using Builtin Ultrasonic Sensor and Quasi-Servo Valve, International Journal of Mechanical Engineering and Robotics Research, Vol.4, No.4, p.304-308 (2015)

13) Matsui, Y., Akagi, T., Dohta. S., Aliff, M. and Liu, C.: Development of Portable Rehabilitation Device Using Flexible Spherical Actuator and Embedded Controller, Lecture Notes in Electrical Engineering 293, Volume 1, Springer, p.231-238 (2014)

14) So Shimooka, Shujiro Dohta, Tetsuya Akagi, Wataru Kobayashi, Masataka Yoneda: Development of Portable Rehabilitation Device Using Flexible Extension Type Soft Actuator with Built-in Small-Sized Quasi Servo Valve and Displacement Sensor, Proceedings of the 10th JFPS International Symposium on Fluid Power 2017, 2B11.pdf, 1-8. (2017)

15) Elliot W. Hawkes, David L. Christensen, Allison M. Okamura: Design and implementation of a $300 \%$ strain soft artificial muscle, 2016 IEEE International Conference on Robotics and Automation, p. 4022-4029 (2016)

16) Ogawa, K.: Evidence-Based Nursing Ergonomics and Body-Mechanics, Tokyo Denki University Press, p.28 (2008) (in Japanese)

17) Ministry of Health, Labour and Welfare: The National Health and Nutrition Survey in Japan, 2016, p.102 (2016)

18) Matsui, Y., Akagi, T. and Dohta. S.: Development of Flexible Displacement Measuring System Using WireType Linear Encoder for Flexible Spherical Actuator, Procedia Computer Science, Vol.76, p.113-118 (2015)
19) Matsui, Y., Akagi, T. and Dohta, S.: Development of LowCost Wire Type Linear Potentiometer for Flexible Spherical Actuator, Proceedings of 2016 IEEE International Conference on Advanced Intelligent Mechatronics AIM2016, 16340660 (2016)

20) Aliff, M., Akagi, T. and Dohta, S.: Trajectory Control of Robot Arm Using Flexible Pneumatic Cylinders and Embedded Controller, Proceedings of 2015 IEEE/ASME International Conference on Advanced Intelligent Mechatronics, p.1120-1125 (2015) 